Article

\title{
Identification of Phenotypic Variation and Genetic Diversity in Rice (Oryza sativa L.) Mutants
}

\author{
Truong Thi Tu Anh ${ }^{1}$, Tran Dang Khanh ${ }^{2}$, Tran Dang Dat ${ }^{3}$ and Tran Dang Xuan ${ }^{1, *(\mathbb{D}}$ \\ 1 Graduate School for International Development and Cooperation, Hiroshima University, \\ 1-5-1 Kagamiyama, Higashi-Hiroshima City, Hiroshima 739-8529, Japan; tuanhbp@gmail.com \\ 2 Agricultural Genetics Institute, Pham Van Dong Street, Hanoi 122300, Vietnam; khanhkonkuk@gmail.com \\ 3 Khai Xuan International Co., Ltd., Cau Giay District, Hanoi 122000, Vietnam; khaixuan.study@gmail.com \\ * Correspondence: tdxuan@hiroshima-u.ac.jp; Tel.: +81-82-424-6927
}

Received: 21 December 2017; Accepted: 20 February 2018; Published: 24 February 2018

\begin{abstract}
In this study, phenotypic variation and genetic diversity, important factors to decide germplasm for rice breeding, were evaluated among 15 rice mutants attained from the MNU (N-Nitroso- $\mathrm{N}$-methylurea) mutation. The correlation coefficient values among these phenotypic characteristics were calculated. The results showed that full grain number per plant was the most relevant factor contributing to grain yield per plant, and grain length to width ratio was the key parameter affected to amylose content. Furthermore, the genetic variation among mutants was estimated by Simple Sequence Repeat (SSR) markers related to amylose content trait. Fifty-six polymorphism markers covering across eleven rice chromosomes were recorded with an average of 3.02 alleles per locus. The average value of polymorphism information content was 0.47 . By using the unweighted pair group method with arithmetic mean (UPGMA) clustering, four clusters were generated with the genetic similarities ranging from 0.52 to 0.91 . The variation among groups was $34 \%$, while the variation among individuals within groups was $66 \%$. Findings of this study provided useful genetic background and phenotypic information of collected rice mutants to breed rice cultivars with improved quality.
\end{abstract}

Keywords: phenotypic variation; genetic diversity; polymorphism information content; mutants; SSR markers; MNU (N-Nitroso- $N$-methylurea) mutation

\section{Introduction}

As an essential food for human beings, rice (Oryza sativa L.) has been widely consumed and planted around the world. Particularly, 80\% of rice production in the world comes from Asian countries [1]. More than half of the world's population constantly includes rice in their diet, and about 2808 calories are provided by rice per person per day [2]. As world population growth and climate change are undeniable, demands for higher yield and better quality rice have become a critical issue [3]. Therefore, breeding new rice varieties with improved quality and productivity is an unprecedented challenge [4].

With assistance from biotechnology, rice breeding targets are not only improving crop productivity, but also upgrading quality characteristics through alterations in heredity [5]. Many tremendous efforts and rapid progresses in rice breeding programs have been carried out and received remarkable achievements [6]. As a result, new rice varieties have been developed and released with higher yield and quality.

Mutation, an effective method applied in many crops, plays a notable role in the development of desired varieties particularly in rice. Mutation may occur naturally due to alterations of base pairs in a DNA sequence [5]. These alterations can be passed from generation to generation; thus, mutation 
is the primary source of genetic variation. In accordance with recombinant breeding and transgenic breeding, mutation is currently the most effective tool of plant breeding, especially throughout sexual production [7]. As the major element of germplasm, genetic diversity is a natural source for rice breeding to encounter existing food requirements [8]. The higher the level of genetic variation is in a population, the more valuable it is as a resource is used for enlarging the genetic base in breeding program [9]. In addition, Haritha et al. [10] postulated that genetic diversity obtained precious information for both basic studies and practical applications. DNA markers have revealed a promising approach toward detecting genetic diversity and assisting in management of plant genetic resources [11]. The differentiations among accessions, individuals, and identification and characterization of novel germplasms at the molecular level, can be recognized by DNA markers and genetic engineering [12]. In association with bioinformatic tools, DNA markers provide favorably successful and reliable technologies to facilitate evaluation of genetic variation in rice. Moreover, DNA markers offer a great promise for rice breeding because of their competence and accuracy [13]. Numerous kinds of molecular markers have been practiced for calculating genetic dissimilarity in rice [14]. Remarkably, among closely related rice cultivars, SSR markers are particularly prominent for evaluation of genetic diversity as they can detect a remarkable great level of polymorphism [11,15].

Chemical mutagens have been used for genetic screens crop breeding. Compounds such as EMS (ethyl methanesulfonate) and MNU ( $N$-Nitroso- $N$-methylurea)-induced single nucleotide changes by alkylation of specific nucleotides $[16,17]$, giving mutations that were high in density and essentially randomly distributed [18]. Therefore, a relatively small population of rice can provide variety of missense changes with differing effects on protein function [19]. In a previous study, Satoh et al. [20] found that using of $\mathrm{N}$-methyl- $\mathrm{N}$-nitrosourea mutation caused effects to the PHO1 gene in rice, which might play some crucial role in starch biosynthesis by forming a functional protein-protein complexed with carbohydrate metabolizing enzymes. The mutant rice lines were produced by treating fertilized egg cells of Japonica rice cultivars (Oryza sativa cv. Kinmaze and T65) [20], and when rice seeds mutated by $\mathrm{MNU}$, the influence on the biosynthesis in rice endosperm, including amylopectin and amylose contents, has not been understood.

Rice grain quality, a persuasive factor for consumer preferences and global commerce, is a combination of physical and chemical characteristics [3]. It is categorized in different major physical and chemical indicators [6] such as appearance quality, milling quality, nutritional quality, cooking and eating quality. Amylose content $(\mathrm{AC})$ is considered as one of the key characteristics for assessment of rice cooking and eating quality [21], and it may also affect some physical traits [3]. Hence, this study was conducted to evaluate the phenotypic variation of rice mutant lines achieved from MNU mutation, to determine the genetic divergence using SSR markers relevant to amylose content trait, and to investigate the alteration of rice germplasms after mutation.

\section{Materials and Methods}

\subsection{Rice Materials}

Fifteen rice mutants and four rice cultivars (all are Indica subtype) provided by Khai Xuan International Co. Ltd. and Agricultural Genetics Institute (Hanoi, Vietnam), respectively, were used in this study. Rice mutants were originated from cultivars, including Bao Thai, DT84, TBR1, Khang dan, SKLo, and BC15TB. To obtain rice mutants, seeds of these origin rice cultivars were soaked in $150 \mathrm{mM}$ MNU (N-Nitroso- $N$-methylurea) for $3 \mathrm{~h}$, dried, and kept in hermetic conditions before used [22]. Information of the rice materials were shown in Table 1. 
Table 1. List of rice materials.

\begin{tabular}{|c|c|c|c|}
\hline $\begin{array}{l}\text { Sample } \\
\text { Codes }\end{array}$ & Origins & Mutants & Descriptions \\
\hline B & $\mathrm{M}_{2}$-Bao thai & + & $\begin{array}{l}\text { Originated from Bao Thai cultivar with good quality, cold tolerance, } \\
\text { cultivated in Northern Midland and Mountainous region in Vietnam }\end{array}$ \\
\hline $\mathrm{D}$ & DT84 & - & A traditional sticky rice with good quality in the north of Vietnam \\
\hline $\mathrm{DB}_{1}$ & $\mathrm{M}_{2}$-DT84/Bao thai & + & $\mathrm{F}_{2}$ mutant line \\
\hline $\mathrm{DB}_{2}$ & $\mathrm{M}_{2}$-DT84/Bao thai & + & $\mathrm{F}_{2}$ mutant line \\
\hline $\mathrm{DB}_{3}$ & $\mathrm{M}_{2}$-DT84/Bao thai & + & $\mathrm{F}_{2}$ mutant line \\
\hline $\mathrm{DDB}_{1}$ & $\mathrm{M}_{2}$-DT84DB & + & $\mathrm{F}_{2}$ mutant line \\
\hline $\mathrm{DDB}_{2}$ & $\mathrm{M}_{2}$-DT84DB & + & $\mathrm{F}_{2}$ mutant line \\
\hline $\mathrm{DDB}_{3}$ & $\mathrm{M}_{2}$-DT84DB & + & $\mathrm{F}_{2}$ mutant line \\
\hline $\mathrm{DDB}_{4}$ & $\mathrm{M}_{2}$-DT84DB & + & $\mathrm{F}_{2}$ mutant line \\
\hline $\mathrm{TK}_{1}$ & $\mathrm{M}_{2}$-TBR1/Khang dan & + & $\mathrm{F}_{2}$ mutant line \\
\hline $\mathrm{TK}_{2}$ & $\mathrm{M}_{2}$-TBR1/Khang dan & + & $\mathrm{F}_{2}$ mutant line \\
\hline $\mathrm{TK}_{3}$ & $\mathrm{M}_{2}$-TBR1/Khang dan & + & $\mathrm{F}_{2}$ mutant line \\
\hline $\mathrm{T}$ & TBR1 & - & $\begin{array}{c}\text { Rice leaf blight tolerance, a high yield cultivar, extensively cultivated } \\
\text { in Vietnam }\end{array}$ \\
\hline K & Khang dan & + & $\begin{array}{l}\text { High quality cultivar, broadly cultivated in the Northern and the } \\
\text { central of Vietnam }\end{array}$ \\
\hline$S$ & SKLo & - & A high yield cultivar, widely cultivated in Vietnam \\
\hline $\mathrm{TB}$ & BC15TB & - & $\begin{array}{l}\text { Good quality, high yield, resistance to bacterial leaf blight and brown } \\
\text { plant hopper, intensively cultivated in Vietnam }\end{array}$ \\
\hline $\mathrm{STB}_{1}$ & $\mathrm{M}_{2}-\mathrm{BC} 15 \mathrm{~TB} / \mathrm{SKLo}$ & + & $\mathrm{F}_{2}$ mutant line \\
\hline $\mathrm{STB}_{2}$ & $\mathrm{M}_{2}-\mathrm{BC} 15 \mathrm{~TB} / \mathrm{SKLo}$ & + & $\mathrm{F}_{2}$ mutant line \\
\hline $\mathrm{STB}_{3}$ & $\mathrm{M}_{2}-\mathrm{BC} 15 \mathrm{~TB} / \mathrm{SKLo}$ & + & $\mathrm{F}_{2}$ mutant line \\
\hline
\end{tabular}

\subsection{Rice Preparation and Field Experiments}

Rice seeds were soaked in $0.1 \% \mathrm{NaOCl}$ for $30 \mathrm{~min}$, and then rigorously washed several times in distilled water. These seeds were sown in Petri plates and placed at $30{ }^{\circ} \mathrm{C}$ in a plant growth chamber for two days for germination. The germinated seeds were transferred into plastic trays in a greenhouse. Two weeks-old seedlings were transplanted into the rice field. The field experiment with three replications was arranged based on randomized complete block design from May to November 2016. The area of plots was $60 \mathrm{~m}^{2}$, and plant spacing was $15 \times 20 \mathrm{~cm}$ with one seedling per hill. Standard fertilizer was applied by hand broadcasting, and weed was managed by chemical herbicide and hand weeding. During the tilling stage until 15 days before harvesting, field water was maintained at approximately $10 \mathrm{~cm}[23]$.

\subsection{Phenotypic Measurement}

For each trait, 10 plants were randomly selected (except border plants). Grain yield characteristics consisting of panicle number per plant, panicle length, grain number per plant, 1000-grain weight, full grain number per plant, grain yield per hectare, primary branching number per panicle, secondary branching number per panicle, were recorded at the maturity stage. Panicle length was measured in centimeters from panicle base to the tip. The weight of 1000 grains was estimated based on the weight of 200 grains. Grain yield per hectare was calculated from grain yield per meter square. Grain length, grain width, and grain length to width ratio were recorded by millimeters using ten random selected grains. The grain length value was obtained by measuring the length of grain, and the grain width value was recorded based on the width of grain. The grain length to width ratio was calculated by dividing length to width [24]. Rice grains were dehusked using an Automatic Rice Husker machine (model TR-250, Kett Electric Laboratory, Tokyo, Japan), and then AC, protein content (PC), and lipid content (LC) were measured by using PGC Shizuoka Seiki PS-500 machine (version 2-12, Shizuoka Seiki Co., Ltd., Shizuoka, Japan).

\subsection{DNA Extraction}

The total genomic DNA of rice was extracted by cetyl-trimethyl ammonium bromide (CTAB) method [25] with some modifications. Rice young leaf $(0.5 \mathrm{~g})$ was cut into small pieces and placed into 
a $2.0 \mathrm{~mL}$ centrifuge tube with balls, and then these tubes were kept in $-80{ }^{\circ} \mathrm{C}$ at least $2 \mathrm{~h}$. These samples were ground into fine powder using the Tissue Lyser II machine (Qiagen, Germany). A volume of $500 \mu \mathrm{L} 2 \%$ hot CTAB buffer was added into each tube and vigorously vortexed. After incubation at $65{ }^{\circ} \mathrm{C}$ for $15 \mathrm{~min}$ in a Block Bath Shaker (MyBL-100S, AS ONE Corp. Japan, Osaka, Japan), the suspensions were centrifuged at $12,000 \mathrm{rpm}$ for $5 \mathrm{~min}$ at $4{ }^{\circ} \mathrm{C}$. The supernatant was gently mixed with $250 \mu \mathrm{L}$ of mixture chloroform: isoamyl alcohol (24:1 ratio) and left for $5 \mathrm{~min}$ at room temperature. After centrifugation at $12,000 \mathrm{rpm}$ for $5 \mathrm{~min}$ at $4{ }^{\circ} \mathrm{C}$, the supernatant was transferred to a new $1.5 \mathrm{~mL}$ microfuge tube, followed by added $500 \mu \mathrm{L}$ of isopropanol to each tube and stored at $-20^{\circ} \mathrm{C}$ at least $1 \mathrm{~h}$. The supernatant was discarded after centrifugation at $12,000 \mathrm{rpm}$ at $4{ }^{\circ} \mathrm{C}$ for $5 \mathrm{~min}$, and the pellet was then washed with an amount of $500 \mu \mathrm{L} 70 \%$ ethanol. The pellet was dried for $15 \mathrm{~min}$ at $37^{\circ} \mathrm{C}$ using an Iwaki Vacuum Centrifugal Evaporator HVC 500 machine (Iwaki Co., Ltd., Tokyo, Japan). A volume of $100 \mu \mathrm{L}$ TE (Tris-EDTA) buffer was added to each tube to dissolve the pellet. The DNA solution was kept in $4{ }^{\circ} \mathrm{C}$ (for short term storage) or $-20^{\circ} \mathrm{C}$ (for long term storage). The quality of DNA was checked by using $0.8 \%$ agarose gel electrophoresis for $45 \mathrm{~min}$ at $50 \mathrm{~V}$. To visualize the DNA resolution under AMZ System Science limited STAGE system ECX-F15M (Vilber Lourmat, Eberhardzell, Germany) $2.5 \mu \mathrm{L}$ Safeview ${ }^{\mathrm{TM}}$ classic (Aplied Biological Materials Inc., Richmond, BC, Canada) was added to $100 \mathrm{~mL}$ of agarose gel.

\subsection{PCR Amplification}

Polymerase chain reaction (PCR) was carried out to genotype of rice mutants and their parents. Eighty-two selected SSR markers, attributed across the genome linked with amylose content QTL traits, were used to evaluate genetic diversity among rice germplasms. Primer sequences, annealing temperature and chromosomal location information were obtained from GRAMENE database [26]. PCR was performed by using Thermal Cycler GenAtlas S machine (ASTEC Co., Ltd, Fukuoka, Japan) with a total volume of $10 \mu \mathrm{L}$ of the mixture containing $0.5 \mu \mathrm{L}$ of template DNA (100 ng), $1 \mu \mathrm{L}$ of $10 \times$ PCR buffer, $0.8 \mu \mathrm{L}$ of $25 \mathrm{mM} \mathrm{MgCl} 2,0.1 \mu \mathrm{L}$ of $1 \mathrm{mM}$ dideoxynucleotides (dNTPs), $0.5 \mu \mathrm{L}$ of $5 \mu \mathrm{M}$ reverse and forward primers, and $0.05 \mu \mathrm{L}$ of 0.5 units Taq DNA polymerase. The volume was raised up to $10 \mu \mathrm{L}$ with deionized nuclease-free water. The PCR program was initiated by denaturation at $94{ }^{\circ} \mathrm{C}$ for $5 \mathrm{~min}$ followed by 35 cycles of $94{ }^{\circ} \mathrm{C}$ for $1 \mathrm{~min}, 55-65^{\circ} \mathrm{C}$ (depend on annealing temperature of each primer) for $1 \mathrm{~min}$ and $72{ }^{\circ} \mathrm{C}$ for $2 \mathrm{~min}$. A final $5 \mathrm{~min}$ incubation at $72{ }^{\circ} \mathrm{C}$ was allowed for the completion of primer extension. The PCR products were resolved on $5 \%$ polyacrylamide gel in $0.5 \times$ TBE (Tris-borate-EDTA) buffer at $150 \mathrm{~V}$ for $90 \mathrm{~min}$ with EZ-VISION R ONE dye as loading buffer $6 \times$ (VWR Life science, Radnor, PA, USA). The PCR product sizes were determined by a standard DNA ladder 100 bp MXL D100 Mixell (Mixell Inc., Hiroshima, Japan), and it was visualized under an ultra-violet (UV) transilluminator using AMZ System Science limited STAGE system ECX-F15M (Vilber Lourmat, Eberhardzell, Germany).

\subsection{Data Analysis}

The phenotypic data were analyzed by SPSS 20.0 package (SPSS Inc., Chicago, IL, USA). The contribution of each trait on amylose content was calculated using regression analysis, and the correlations among phenotypic characters were determined by Pearson correlation.

The genetic relationship among rice mutants was identified using data obtained from polymorphic markers. The amplified products of each marker were scored as 1 for the presence and 0 for the absence in a binary matrix [27]. The similarity coefficient values were used to construct a dendrogram by NTSYSpc 2.10m software (Steauket, Exeter software, New York, NY, USA), and it was carried out using method of unweighted pair group method with arithmetic mean (UPGMA) to group individuals into clusters [10]. 
The heterozygosity $(\mathrm{H})$ and polymorphic information content (PIC) values of a locus were calculated as described by Nagy et al. [28] with the following formula:

$$
\mathrm{H}=1-\sum_{i=1}^{l} P_{i}^{2}
$$

where $P_{i}$ is the frequency for the $i$ th allele among total of $l$ alleles:

$$
\mathrm{PIC}=1-\sum_{i=1}^{l} P_{i}^{2}-\sum_{i=1}^{l-1} \sum_{j=n+1}^{l} 2 P_{i}^{2} P_{j}^{2}
$$

where $P_{i}$ and $P_{j}$ are the population frequencies of the $i$ th and $j$ th allele.

To identify the genetic differentiation among groups and within groups, AMOVA (analysis of molecular variance) was analyzed using the data of locus by locus of each marker. The significance of estimated variance components was calculated by GenAlex software version 6.503 (Australian National University, Canberra, Australia) following 999 random permutations [29].

\section{Results}

\subsection{Grain Yield and Yield Components}

The results of grain yield measurement were presented in Table 2. These results showed a wide variation among rice mutants. Grain number per plant ranged from 815 to 3081 , with the mean of 1730 , and 1000-grain weight ranged from 18.10 to $25.90 \mathrm{~g}$ with an average of $22.35 \mathrm{~g}$. The average of grain yield per hectare was 7.87 ton. The relationships between grain yield and the other traits were shown in Figure 1. Results showed that grain yield increased linear with full grain number per plant $\left(R^{2}=0.92, p=0.05\right)$, and it had a light linear with panicle number per plant $\left(R^{2}=0.15, p=0.05\right)$ and 1000-grain weight $\left(R^{2}=0.07, p=0.05\right)$ (Figure 1$)$.

Table 2. Variability of phenotypic traits.

\begin{tabular}{ccccc}
\hline Characteristics & Mean & Range & SD & CV (\%) \\
\hline Panicle number per plant & 7.23 & $2-12$ & 2.24 & 3.22 \\
Panicle length (cm) & 24.58 & $19.70-29.40$ & 2.08 & 11.80 \\
Grain number per plant & 1,730 & $815-3081$ & 543 & 3.18 \\
1000-grain weight (g) & 22.35 & $18.10-25.90$ & 1.90 & 1.90 \\
Full grain number per plant & 1,067 & $442-1791$ & 306 & 3.48 \\
Grain yield per hecta (ton) & 7.87 & $2.64-15.31$ & 2.39 & 3.29 \\
Primary branching number per panicle & 13.46 & $10-18$ & 1.74 & 7.76 \\
Secondary branching number per panicle & 56.25 & $27-87$ & 14.96 & 3.76 \\
Grain length (mm) & 5.81 & $4.87-6.52$ & 0.48 & 12.10 \\
Grain width (mm) & 2.41 & $2.10-2.78$ & 0.21 & 11.23 \\
Grain length to width ratio (mm) & 2.44 & $1.86-2.97$ & 0.38 & 6.49 \\
Amylose content (\%) & 22.43 & $17.30-24.90$ & 2.06 & 10.91 \\
Protein content (\%) & 6.41 & $1.40-11.30$ & 2.41 & 2.66 \\
Lipid content (\%) & 8.78 & $1-17$ & 4.97 & 1.77 \\
\hline
\end{tabular}




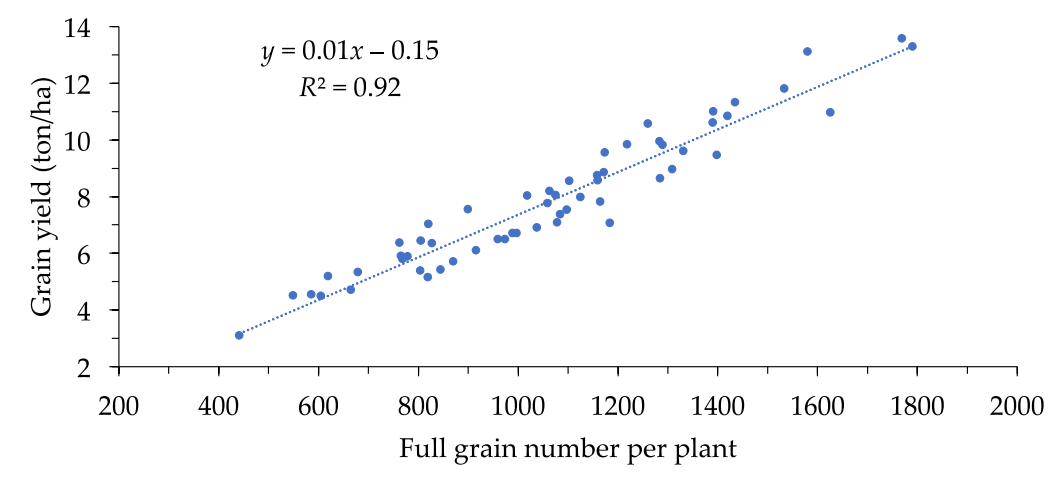

- Grain yield (ton/ha) ……. Linear (Grain yield (ton/ha)

(a)

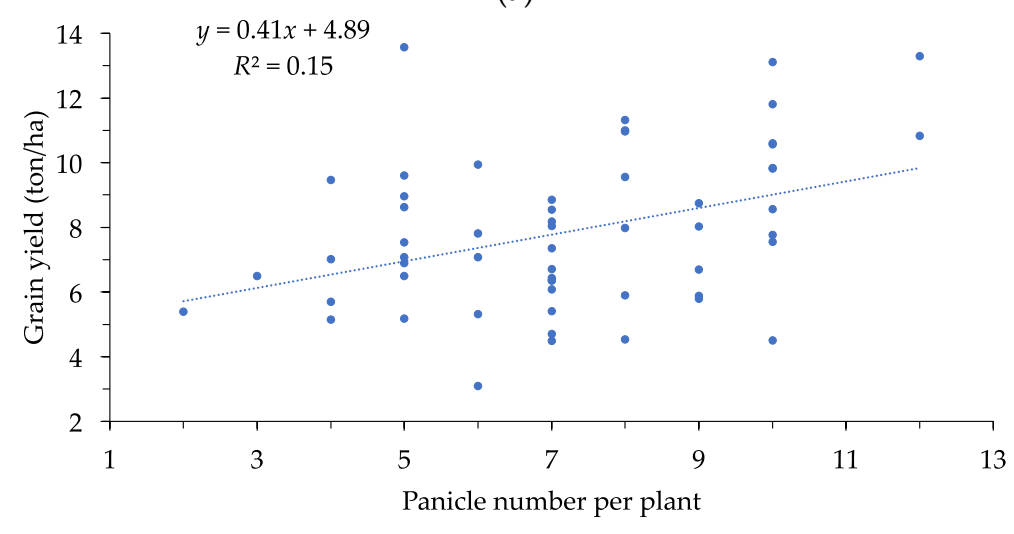

- Grain yield (ton/ha) …… Linear (Grain yield (ton/ha)

(b)

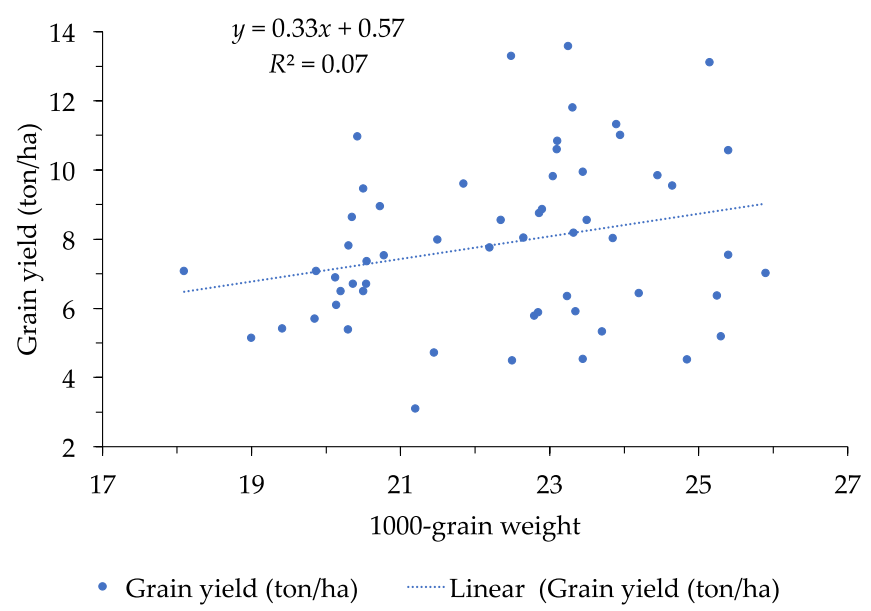

(c)

Figure 1. Relationship between grain yield and (a) full grain number per plant, (b) panicle number per plant, and (c) 1000-grain weight.

\subsection{Grain Size and Chemical Quality Traits}

The grain length varied from 4.87 to $6.52 \mathrm{~mm}$ with the mean of $5.81 \mathrm{~mm}$, while grain weight ranged from 2.10 to $2.78 \mathrm{~mm}$ with the mean of $2.41 \mathrm{~mm}$. The grain length to width ratio ranged from 1.86 to $2.97 \mathrm{~mm}$ with the mean of $2.44 \mathrm{~mm}$ (Table 2). According to IRRI (International Rice Research Institute) classification, rice mutants generally had long size (grain length $>5.5 \mathrm{~mm}$, and grain length to width ratio $>2.00 \mathrm{~mm}$ ). 
The AC ranged from $17.30 \%$ to $24.90 \%$ with mean of $22.43 \%$ (Table 2 ). The relationships between $\mathrm{AC}$ and the other traits were shown in Figure 2. Results showed that AC had a linear with grain size; in which, AC increased linearly with grain length to width ratio $\left(R^{2}=0.51, p=0.05\right)$, and it had a slight linear with grain length and grain width $\left(R^{2}=0.43\right.$, and $\left.R^{2}=0.48, p=0.05\right)$. Moreover, AC had no linear with PC $\left(R^{2}=0.00, p=0.05\right)$, and slight linear with LC and panicle length $\left(R^{2}=0.34, R^{2}=0.43, p=0.05\right)$.

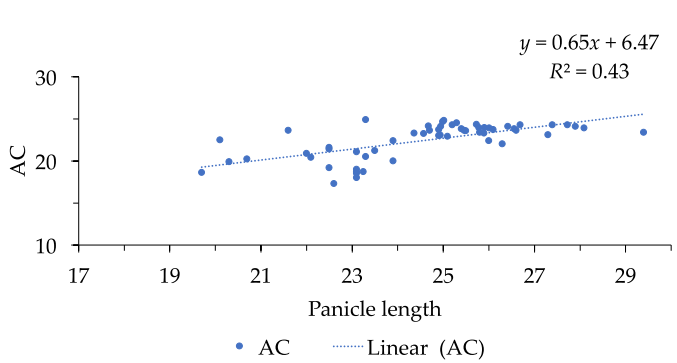

(a)

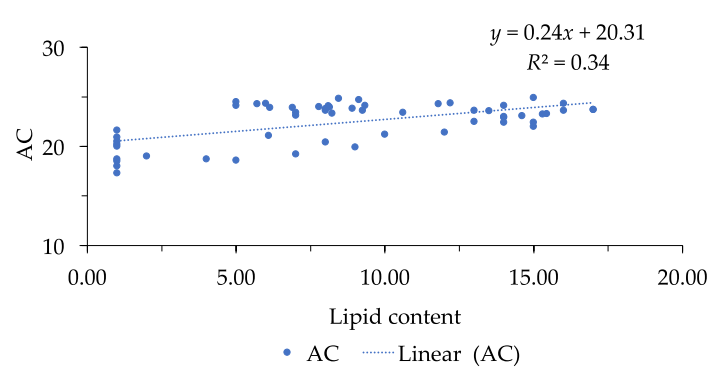

(c)

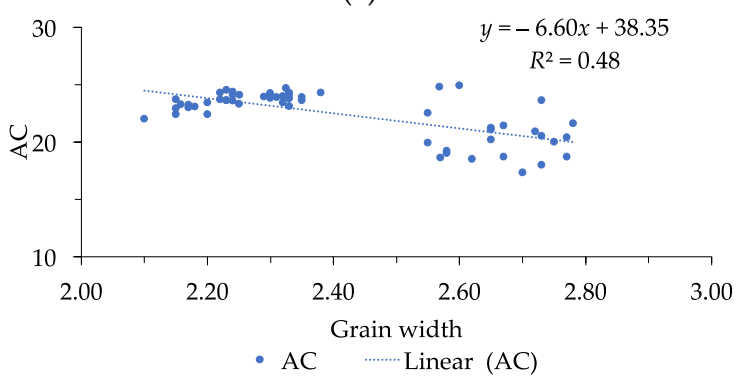

(e)

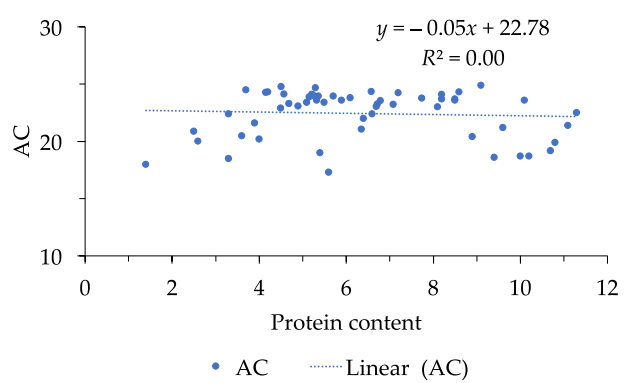

(b)

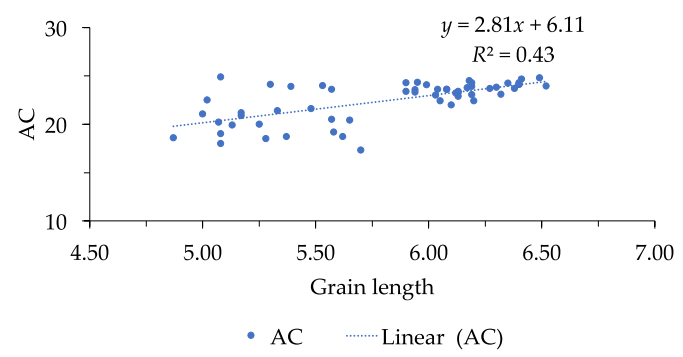

(d)

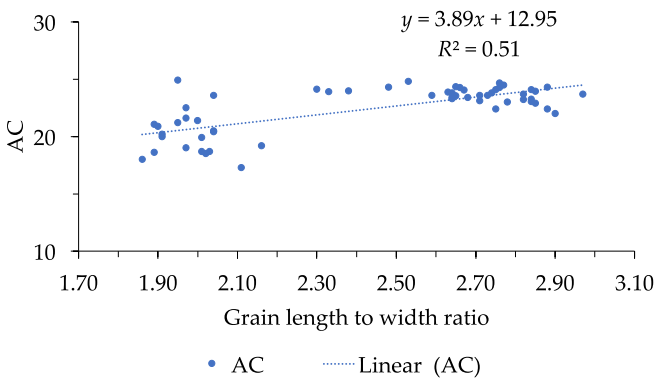

(f)

Figure 2. Relationship between amylose content and (a) panicle length, (b) protein content, (c) lipid content, (d) grain length, (e) grain width, (f) grain length to width ratio.

\subsection{Correlation among Physico-Chemical Traits and Grain Yield}

The correlation coefficients among phenotypic traits were shown in Table 3. The grain yield per hectare was significantly positively correlated with full grain number per plant $(r=0.96, p=0.01)$, panicle number per plant $(r=0.39, p=0.01)$. Grain length and grain length to width ratio had a significantly positive correlation with panicle length $(r=0.74, p=0.01)$. Meanwhile, grain width had significantly negative correlation with panicle length $(r=-0.67, p=0.01)$, and it had significantly positively correlated with 1000-grain weight $(r=0.62, p=0.01)$. Grain length and grain length to width ratio were negatively correlated with 1000-grain weight $(r=-0.28, r=-0.48, p=0.01)$. 
Table 3. Pearson correlation coefficients among phenotypic traits.

\begin{tabular}{|c|c|c|c|c|c|c|c|c|c|c|c|c|c|}
\hline Traits & PNP & PL & GPP & KGW & FGP & GY & PB & SB & GL & GW & LWR & PC & $\mathrm{AC}$ \\
\hline PL & $-0.45^{* *}$ & 1 & & & & & & & & & & & \\
\hline GPP & 0.01 & $0.43^{* *}$ & 1 & & & & & & & & & & \\
\hline KGW & $0.48^{* *}$ & -0.25 & $-0.49^{* *}$ & 1 & & & & & & & & & \\
\hline FGP & $0.26 * *$ & $0.29 *$ & $0.44^{* *}$ & 0.09 & 1 & & & & & & & & \\
\hline GY & $0.39 * *$ & $0.22 *$ & $0.29 *$ & 0.26 & $0.96^{* *}$ & 1 & & & & & & & \\
\hline $\mathrm{PB}$ & $-0.62 * *$ & $0.67 * *$ & $0.59 * *$ & $-0.58^{* *}$ & 0.17 & 0.00 & 1 & & & & & & \\
\hline SB & $-0.56^{* *}$ & $0.68^{* *}$ & $0.68^{* *}$ & $-0.66^{* *}$ & 0.19 & 0.0 & $0.89^{* *}$ & 1 & & & & & \\
\hline GL & $-0.30^{*}$ & $0.74^{* *}$ & $0.48^{* *}$ & $-0.28 *$ & $0.45^{* *}$ & $0.36^{* *}$ & $0.60^{* *}$ & $0.59 * *$ & 1 & & & & \\
\hline GW & $0.65^{* *}$ & $-0.67^{* *}$ & $-0.45^{* *}$ & $0.62 * *$ & -0.70 & 0.10 & $-0.78 * *$ & $-0.81^{* *}$ & $-0.72 * *$ & 1 & & & \\
\hline LWR & $-0.53^{* *}$ & $0.74^{* *}$ & $0.49^{* *}$ & $-0.48^{* *}$ & $0.27^{*}$ & 0.13 & $0.75^{* *}$ & $0.75^{* *}$ & $0.92^{* *}$ & $-0.93^{* *}$ & 1 & & \\
\hline PC & -0.03 & $-0.34 *$ & -0.17 & -0.22 & -0.15 & -0.21 & -0.09 & -0.19 & -0.13 & 0.09 & -0.12 & 1 & \\
\hline AC & $-0.31 *$ & $0.66^{* *}$ & $0.37 * *$ & $-0.35^{* *}$ & 0.19 & 0.86 & $0.49^{* *}$ & $0.53^{* *}$ & $0.66^{* *}$ & $-0.69 * *$ & $0.71^{* *}$ & -0.06 & 1 \\
\hline $\mathrm{LC}$ & $-0.56^{* *}$ & 0.26 & 0.20 & $-0.52^{* *}$ & -0.28 & -0.18 & $0.51 * *$ & $0.44^{* *}$ & $0.49^{* *}$ & $-0.67^{* *}$ & $0.64^{* *}$ & $0.47^{* *}$ & $0.58^{* *}$ \\
\hline
\end{tabular}

** *: correlation is significant at the 0.01 and 0.05 levels, respectively; PNP: panicle number per plant; PL: panicle length; GPP: grain number per plant; KGW: 1000 -grain weight; FGP: full grain number per plant; GY: grain yield per hectare; PB: primary branching number per panicle; SB: secondary branching number per panicle; GL: grain length; GW: grain width; LWR: grain length to width ratio; AC: amylose content; PC: protein content; LC: lipid content. 
The correlation between appearance quality and nutritional quality was listed in Table 3. AC had a significantly positive correlation with grain length and grain length to width ratio, whereas AC had a significantly negative correlation with grain width. The significantly positive correlation was found between AC and panicle length $(r=0.66, p=0.01)$. Data in Table 3 also showed that there was a negative correlation between grain length and grain width $(r=-0.72, p=0.01)$, whereas grain length had an absolutely positive correlation with grain length to width ratio $(r=0.92, p=0.01)$.

\subsection{Genetic Diversity}

A total of 82 SSR markers, randomly dispersed across on 12 chromosomes of rice, were used to evaluate the genetic diversity of the rice genotypes. Fifty-six polymorphism SSR markers distributed on 11 chromosomes of rice were detected (Table 4). A total of 167 alleles were identified, and the number of alleles ranged from 2 to 7 with an average of 3.02 alleles per locus.

Table 4. Profiles of Simple Sequence Repeat (SSR) markers.

\begin{tabular}{|c|c|c|c|c|c|c|c|c|}
\hline No & Marker Name & Repeat Sequence & Chromosome & Allele & Total Alleles & Ho & $\mathbf{H}$ & PIC \\
\hline 1 & RM190 & $(\mathrm{CT})_{11}$ & 6 & 2 & 20 & 0.05 & 0.48 & 0.36 \\
\hline 2 & RM510 & $(\mathrm{GA})_{15}$ & 6 & 2 & 18 & 0.05 & 0.44 & 0.34 \\
\hline 3 & RM508 & $(\mathrm{AG})_{17}$ & 6 & 3 & 18 & 0.05 & 0.58 & 0.50 \\
\hline 4 & RM540 & $(\mathrm{AG})_{16}$ & 6 & 2 & 19 & 1.00 & 0.33 & 0.28 \\
\hline 5 & RM170 & $(\mathrm{CCT})_{7}$ & 6 & 2 & 26 & 0.37 & 0.50 & 0.38 \\
\hline 6 & RM2 & $(\mathrm{GA})_{13}$ & 7 & 5 & 42 & 0.21 & 0.76 & 0.73 \\
\hline 7 & RM2010 & $(\mathrm{AT})_{19}$ & 5 & 3 & 19 & 0.05 & 0.62 & 0.54 \\
\hline 8 & RM587 & $(\mathrm{CTT})_{18}$ & 6 & 2 & 23 & 0.26 & 0.49 & 0.37 \\
\hline 9 & RM219 & $(\mathrm{CT})_{17}$ & 9 & 6 & 41 & 1.00 & 0.79 & 0.76 \\
\hline 10 & RM107 & $(\mathrm{GA})_{7}$ & 9 & 2 & 16 & 0.16 & 0.47 & 0.36 \\
\hline 11 & RM225 & $(\mathrm{CT})_{18}$ & 6 & 3 & 19 & 0.16 & 0.59 & 0.50 \\
\hline 12 & RM111 & $(\mathrm{GA})_{9}$ & 6 & 2 & 32 & 0.89 & 0.50 & 0.37 \\
\hline 13 & RM229 & $(\mathrm{TC})_{11}(\mathrm{CT})_{5} \mathrm{C}_{3}(\mathrm{CT})_{5}$ & 11 & 2 & 18 & 0.05 & 0.44 & 0.33 \\
\hline 14 & RM434 & $(\mathrm{TC})_{12}$ & 9 & 4 & 31 & 1.00 & 0.64 & 0.58 \\
\hline 15 & RM584 & $(\mathrm{CT})_{14}$ & 6 & 4 & 31 & 1.00 & 0.73 & 0.68 \\
\hline 16 & RM5688 & $(\mathrm{AAT})_{17}$ & 9 & 3 & 16 & 0.47 & 0.62 & 0.54 \\
\hline 17 & RM287 & $(\mathrm{GA})_{21}$ & 11 & 2 & 20 & 0.05 & 0.48 & 0.36 \\
\hline 18 & RR6119 & $(\mathrm{CGC})_{8}$ & 6 & 4 & 24 & 1.00 & 0.40 & 0.38 \\
\hline 19 & RM402 & $(\mathrm{ATA})_{7}$ & 6 & 3 & 21 & 0.11 & 0.61 & 0.54 \\
\hline 20 & RM55 & $(\mathrm{GA})_{17}$ & 3 & 3 & 14 & 0.26 & 0.50 & 0.43 \\
\hline 21 & RM14 & $(\mathrm{GA})_{18}$ & 1 & 2 & 18 & 0.05 & 0.20 & 0.18 \\
\hline 22 & RM18 & $(\mathrm{GA})_{4} \mathrm{AA}(\mathrm{GA})(\mathrm{AG})_{16}$ & 7 & 4 & 29 & 0.05 & 0.71 & 0.66 \\
\hline 23 & RM22 & (GA) 22 & 3 & 2 & 18 & 0.16 & 0.40 & 0.32 \\
\hline 24 & RM19 & $(\mathrm{ATC})_{10}$ & 12 & 4 & 29 & 0.05 & 0.65 & 0.59 \\
\hline 25 & RM222 & $(\mathrm{GT})_{3}(\mathrm{GTAT})_{8}(\mathrm{GT})_{5}$ & 10 & 3 & 19 & 0.11 & 0.62 & 0.55 \\
\hline 26 & RM239 & $(\mathrm{AG})_{5} \mathrm{TG}(\mathrm{AG})_{2}$ & 10 & 4 & 42 & 1.00 & 0.74 & 0.69 \\
\hline 27 & RM311 & $(\mathrm{GT})_{3}(\mathrm{GTAT})_{8}(\mathrm{GT})_{5}$ & 10 & 2 & 25 & 0.95 & 0.50 & 0.37 \\
\hline 28 & RM251 & $(\mathrm{CT})_{29}$ & 3 & 2 & 18 & 0.05 & 0.40 & 0.32 \\
\hline 29 & RM4 & $(\mathrm{GA})_{16}$ & 1 & 4 & 49 & 1.00 & 0.71 & 0.67 \\
\hline 30 & RM213 & $(\mathrm{CT})_{17}$ & 2 & 4 & 29 & 1.00 & 0.62 & 0.58 \\
\hline 31 & RM432 & $(\text { CATC })_{9}$ & 7 & 2 & 14 & 0.16 & 0.49 & 0.37 \\
\hline 32 & RM38 & $(\mathrm{GA})_{16}$ & 8 & 3 & 18 & 0.11 & 0.65 & 0.57 \\
\hline 33 & RM52 & $(\mathrm{AG})_{19}$ & 8 & 2 & 24 & 0.47 & 0.50 & 0.38 \\
\hline 34 & RM218 & $(\mathrm{TC})_{24} \mathrm{ACT}_{5}(\mathrm{GT})_{11}$ & 3 & 3 & 20 & 1.00 & 0.62 & 0.53 \\
\hline 35 & RM504 & $(\mathrm{CA})_{9}$ & 3 & 5 & 59 & 0.05 & 0.78 & 0.74 \\
\hline 36 & RM426 & $(\mathrm{CA})_{10}$ & 3 & 7 & 50 & 1.00 & 0.81 & 0.79 \\
\hline 37 & RM247 & $(\mathrm{CT})_{16}$ & 12 & 2 & 20 & 0.16 & 0.32 & 0.27 \\
\hline 38 & RM3392 & $(\mathrm{CT})_{17}$ & 3 & 2 & 19 & 1.00 & 0.47 & 0.36 \\
\hline 39 & RM569 & $(\mathrm{CT})_{16}$ & 3 & 3 & 29 & 0.63 & 0.66 & 0.59 \\
\hline 40 & RM234 & $(\mathrm{CT})_{25}$ & 7 & 2 & 18 & 1.00 & 0.50 & 0.38 \\
\hline 41 & RM284 & $(\mathrm{GA})_{8}$ & 8 & 2 & 19 & 1.00 & 0.20 & 0.18 \\
\hline 42 & RM338 & $(\mathrm{CTT})_{6}$ & 3 & 5 & 52 & 1.00 & 0.77 & 0.74 \\
\hline 43 & RM228 & $(\mathrm{CA})_{6}(\mathrm{GA})_{36}$ & 10 & 3 & 25 & 0.16 & 0.62 & 0.54 \\
\hline 44 & RM431 & $(\mathrm{AG})_{16}$ & 1 & 6 & 67 & 0.05 & 0.81 & 0.79 \\
\hline 45 & RM333 & $(\mathrm{TAT})_{19}(\mathrm{CTT})_{19}$ & 10 & 6 & 58 & 1.00 & 0.81 & 0.78 \\
\hline 46 & RM472 & $(\mathrm{GA})_{21}$ & 1 & 4 & 29 & 0.05 & 0.71 & 0.66 \\
\hline 47 & RM5626 & $(\mathrm{AAG})_{11}$ & 3 & 3 & 35 & 0.26 & 0.66 & 0.58 \\
\hline 48 & RM7 & $(\mathrm{GA})_{19}$ & 3 & 2 & 17 & 0.05 & 0.41 & 0.33 \\
\hline 49 & RM230 & $(\mathrm{AGG})_{4}(\mathrm{GA})_{9} \mathrm{~A}(\mathrm{AG})_{13}$ & 8 & 2 & 24 & 0.37 & 0.50 & 0.38 \\
\hline 50 & RM162 & $(\mathrm{AC})_{20}$ & 6 & 2 & 21 & 0.74 & 0.47 & 0.36 \\
\hline 51 & RM413 & $(\mathrm{AG})_{11}$ & 5 & 2 & 19 & 1.00 & 0.47 & 0.36 \\
\hline 52 & RM593 & $(\mathrm{CT})_{15}(\mathrm{CA})_{10}$ & 5 & 2 & 20 & 1.00 & 0.46 & 0.35 \\
\hline 53 & RM247 & $(\mathrm{CT})_{16}$ & 12 & 3 & 23 & 0.11 & 0.63 & 0.56 \\
\hline 54 & RM60 & $(\mathrm{AATT})_{5} \mathrm{AATCT}(\mathrm{AATT})$ & 3 & 2 & 19 & 1.00 & 0.10 & 0.09 \\
\hline 55 & RM264 & $(\mathrm{GA})_{27}$ & 8 & 2 & 19 & 1.00 & 0.47 & 0.36 \\
\hline 56 & RM589 & $(\mathrm{GT})_{24}$ & 6 & 2 & 18 & 1.00 & 0.28 & 0.24 \\
\hline
\end{tabular}

Ho: observed heterozygosity per marker; H: Heterozygosity; PIC: Polymorphism information content. 
The $\mathrm{H}$ values ranged from 0.10 to 0.81 with an average 0.55 . The PIC values varied from 0.09 to 0.79 with an average of 0.47 . There were 28 highly informative markers (PIC $>0.5$ ), 24 moderately informative markers $(0.25<$ PIC $<0.5)$ and only four slightly informative markers (PIC $<0.25$ ). RM426 and RM431 showed the maximum PIC value and $H$ value (0.79 and 0.81 ); whereas, RM60 showed the minimum PIC and H values (0.09 and 0.10). The markers RM2, RM219, RM504, RM426, RM338, RM431, RM333 showed great PIC value $(0.73<$ PIC < 0.79$)$. A dendrogram constructed by UPGMA based clustering analysis divided rice mutants into four major clusters with the similarity coefficients ranging from 0.52 to 0.91 (Figure 3). Furthermore, the genetic similarity between rice mutants and their relatives was presented in Table 5.

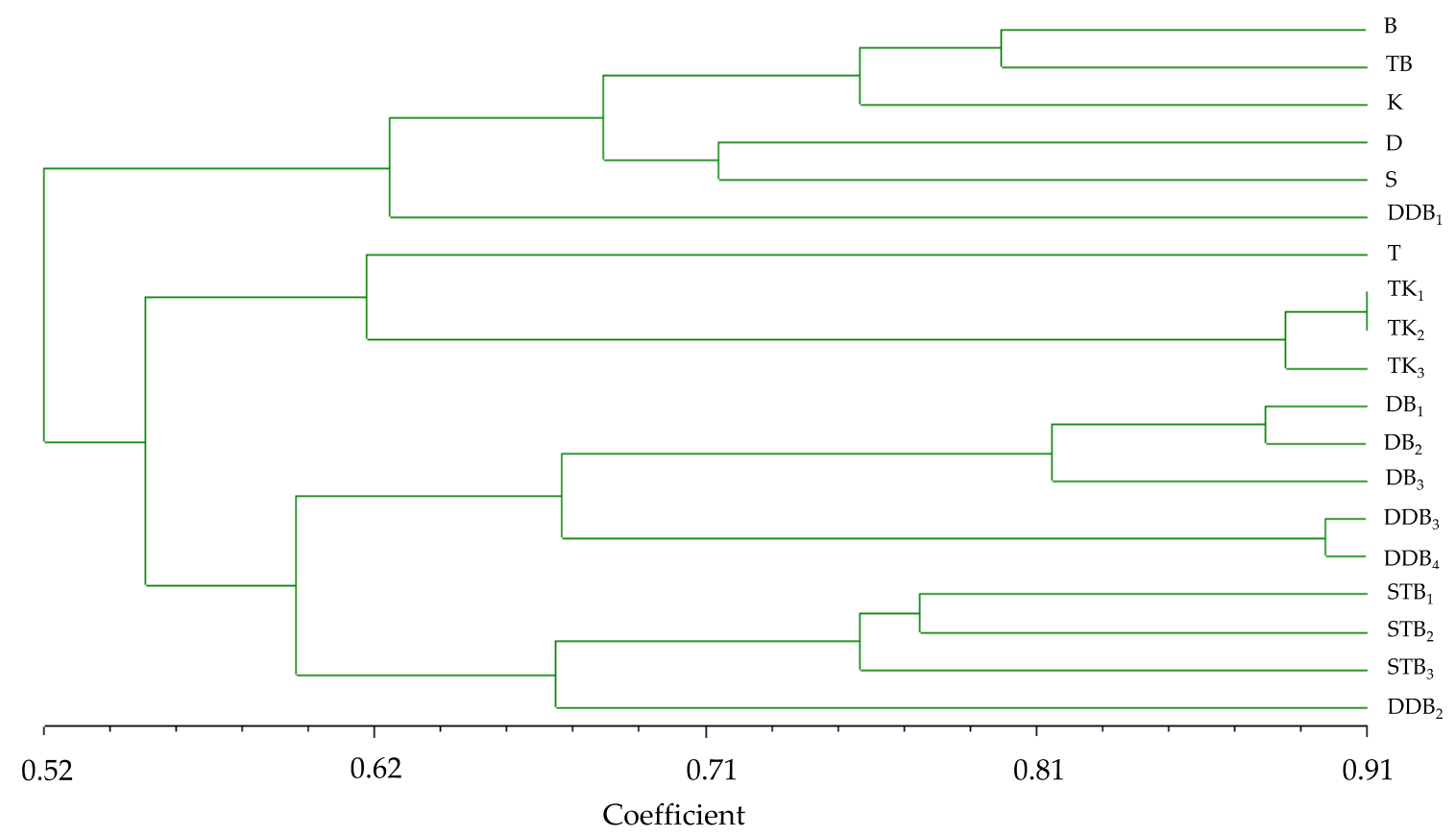

Figure 3. Cluster diagram of rice mutants and their origins.

Table 5. Genetic similarity of rice mutants and their origins.

\begin{tabular}{|c|c|c|c|c|c|c|c|c|c|c|c|c|c|c|c|c|c|c|}
\hline Name & B & $\mathrm{D}$ & $\mathrm{DDB}_{1}$ & TB & $S$ & $T$ & $\mathrm{~K}$ & $\mathrm{DB}_{1}$ & $\mathrm{DB}_{2}$ & $\mathrm{DB}_{3}$ & $\mathrm{TK}_{1}$ & $\mathrm{TK}_{2}$ & $\mathrm{TK}_{3}$ & $\mathrm{STB}_{1}$ & $\mathrm{STB}_{2}$ & $\mathrm{STB}_{3}$ & $\mathrm{DDB}_{2}$ & $\mathrm{DDB}_{3}$ \\
\hline B & 1 & & & & & & & & & & & & & & & & & \\
\hline $\mathrm{D}$ & 0.71 & 1 & & & & & & & & & & & & & & & & \\
\hline $\mathrm{DDB}_{1}$ & 0.60 & 0.67 & 1 & & & & & & & & & & & & & & & \\
\hline TB & 0.80 & 0.69 & 0.58 & 1 & & & & & & & & & & & & & & \\
\hline$S$ & 0.70 & 0.72 & 0.61 & 0.61 & 1 & & & & & & & & & & & & & \\
\hline $\mathrm{T}$ & 0.54 & 0.62 & 0.56 & 0.63 & 0.69 & 1 & & & & & & & & & & & & \\
\hline K & 0.74 & 0.60 & 0.64 & 0.78 & 0.64 & 0.52 & 1 & & & & & & & & & & & \\
\hline $\mathrm{DB}_{1}$ & 0.48 & 0.50 & 0.49 & 0.50 & 0.51 & 0.50 & 0.48 & 1 & & & & & & & & & & \\
\hline $\mathrm{DB}_{2}$ & 0.53 & 0.54 & 0.54 & 0.56 & 0.55 & 0.53 & 0.49 & 0.88 & 1 & & & & & & & & & \\
\hline $\mathrm{DB}_{3}$ & 0.49 & 0.49 & 0.56 & 0.52 & 0.54 & 0.51 & 0.50 & 0.80 & 0.82 & 1 & & & & & & & & \\
\hline $\mathrm{TK}_{1}$ & 0.53 & 0.54 & 0.54 & 0.51 & 0.56 & 0.63 & 0.46 & 0.55 & 0.57 & 0.63 & 1 & & & & & & & \\
\hline $\mathrm{TK}_{2}$ & 0.50 & 0.50 & 0.41 & 0.48 & 0.49 & 0.58 & 0.41 & 0.53 & 0.54 & 0.60 & 0.91 & 1 & & & & & & \\
\hline $\mathrm{TK}_{3}$ & 0.52 & 0.53 & 0.46 & 0.49 & 0.50 & 0.63 & 0.43 & 0.53 & 0.51 & 0.55 & 0.88 & 0.89 & 1 & & & & & \\
\hline $\mathrm{STB}_{1}$ & 0.58 & 0.51 & 0.50 & 0.52 & 0.49 & 0.49 & 0.54 & 0.57 & 0.57 & 0.61 & 0.64 & 0.63 & 0.66 & 1 & & & & \\
\hline $\mathrm{STB}_{2}$ & 0.52 & 0.55 & 0.53 & 0.51 & 0.51 & 0.53 & 0.45 & 0.59 & 0.63 & 0.64 & 0.58 & 0.58 & 0.61 & 0.78 & 1 & & & \\
\hline $\mathrm{STB}_{3}$ & 0.56 & 0.48 & 0.47 & 0.54 & 0.51 & 0.47 & 0.49 & 0.56 & 0.57 & 0.51 & 0.59 & 0.58 & 0.59 & 0.76 & 0.75 & 1 & & \\
\hline $\mathrm{DDB}_{2}$ & 0.54 & 0.51 & 0.51 & 0.51 & 0.50 & 0.48 & 0.49 & 0.58 & 0.57 & 0.57 & 0.54 & 0.58 & 0.60 & 0.63 & 0.70 & 0.67 & 1 & \\
\hline $\mathrm{DDB}_{3}$ & 0.54 & 0.57 & 0.54 & 0.55 & 0.52 & 0.52 & 0.56 & 0.63 & 0.70 & 0.65 & 0.47 & 0.50 & 0.51 & 0.58 & 0.67 & 0.56 & 0.63 & 1 \\
\hline $\mathrm{DDB}_{4}$ & 0.59 & 0.54 & 0.53 & 0.55 & 0.53 & 0.53 & 0.55 & 0.64 & 0.73 & 0.66 & 0.50 & 0.50 & 0.52 & 0.59 & 0.69 & 0.56 & 0.59 & 0.89 \\
\hline
\end{tabular}

Cluster I included six genotypes, and its similarity coefficient varied from 0.58 to 0.80 . Four genotypes contributed to cluster II with the similarity coefficient from 0.58 to 0.91 . The similarity 
coefficients among $\mathrm{TK}_{1}, \mathrm{TK}_{2}$, and $\mathrm{TK}_{3}$ varied from 0.88 to 0.91 . In which, $\mathrm{TK}_{1}$ and $\mathrm{TK}_{2}$ had the genetic similarity of 0.91 (the highest genetic similarity). The genetic similarity between $\mathrm{T}$ and $\mathrm{TK}_{1}, \mathrm{TK}_{2}$, and $\mathrm{TK}_{3}$ was 0.58 to 0.63 . Cluster III comprised of five genotypes originated from $\mathrm{B}, \mathrm{D}$, and mutant lines $\mathrm{DDB}_{3}, \mathrm{DDB}_{4}$. In this cluster, the similarity coefficient varied from 0.63 to 0.89 . Four genotypes generated from $\mathrm{S}, \mathrm{TB}$, and mutant line $\mathrm{DDB}_{2}$ grouped into cluster IV. $\mathrm{STB}_{1}, \mathrm{STB}_{2}$, and $\mathrm{STB}_{3}$ were generated from $\mathrm{S}$ and $\mathrm{TB}$; while $\mathrm{DDB}_{2}$ has the same origin with $\mathrm{DDB}_{1}, \mathrm{DDB}_{3}$, and $\mathrm{DDB}_{4}$. The similarity coefficient of this cluster ranged from 0.63 to 0.78 (Table 5).

The AMOVA analysis revealed that there was a greatly significant genetic differentiation among groups and within groups. In which, the genetic variation was $34 \%$ among groups, whereas among individuals within groups, there was $66 \%$ of variation (Table 6 ).

Table 6. Differentiation among and within four groups of mutant genotypes by AMOVA.

\begin{tabular}{ccccccc}
\hline Source & $d f$ & SS & MS & Est. Var. & $\%$ & $p$ Value \\
\hline Among groups & 3 & 260.66 & 86.89 & 13.04 & 34 & 0.001 \\
Within groups & 15 & 383.55 & 25.57 & 25.57 & 66 & 0.001 \\
Total & 18 & 644.21 & & 38.61 & 100 & \\
\hline
\end{tabular}

AMOVA: Analysis of molecular variance; $d f$ : degrees of freedom; SS: sum of squares deviation; MS: mean squared deviation; Est. Var.: estimates of variance component; \%: percentage of total variance contributed by each component.

\section{Discussion}

In this study, the rice materials were cultivated in the rice field to measure the variation in quality and yield characteristics. They were also genotyped to clarify the role of mutation. The results showed that both grain yield per plant and amylose content were varied among cultivars and mutant lines. The association among traits is a principal feature that may assist the selection of elite characteristics in breeding programs not only for rice but also for the other plants [6,30]. Discovered the role and the relationship of characteristics related to quality trait in rice is important to develop new varieties with expected quality [6]. Three main constituents of grain yield include number of panicles per plant, number of grains per panicle, and grain weight. Among them, grain weight, measured as 1000-grain weight, is a decisive trait to grain yield [12,31]. In this study, the highest significantly positive correlation was found between grain yield per plant and full grain number per plant, followed by number of panicles per plant and grain weight. This suggested that full grain number per plant has the highest contribution to grain yield, and an increase in full grain number per plant leads to an increase in grain yield.

Grain size is considered as a major determinant of grain appearance quality and grain weight, and it was contributed by grain length, grain width, and grain length to width ratio [12]. Our study agreed with many findings showed that grain weight was significantly correlated with grain size [12,31,32]. This result implied that the larger the grain, the heavier the grain. However, it is difficult for breeders to improve grain size efficiently by phenotyping, since this trait is quantitatively inherited although plants with large seed size were selected for breeding [12].

The correlation between appearance quality and nutritional quality was also found in this research. $\mathrm{AC}$ and protein content are two essential indicators for eating, cooking, and nutritional quality, respectively [6]. With regards to $\mathrm{AC}$ and grain size, our results were consistent with that previously reported by $\mathrm{Xu}$ et al. [33] and Abacar et al. [6]. The significant correlation between AC and grain size suggested that selection of rice mutants with high values of grain length and grain length to width ratio could result in positive response of AC. The involvement of grain length to width ratio in AC was greater than the other traits, and grain length to width ratio was the most significant character influencing AC. Therefore, rice with high grain length to width ratio leads to an increase in AC in rice [6]. Interestingly, this study also found that there was no correlation between PC and grain size. In a previous study, Lou et al. [34] stated that there was no significant correlation between AC and other quality traits. 
It was reasoned that the principal element that regulates AC was a combination of the $W x$ gene with the other minor QTLs. This finding proposed that marker-assisted selection can apply for AC. Furthermore, Abacar et al. [6] highlighted that it was difficult to explain the relationship between AC and the other traits. Additionally, Huang et al. [31] stated that there was a positive correlation between grain weight and grain size; however, the level of correlation of them was differed from independent studies.

In general, there was a dissimilarity in grain yield and AC among the rice mutants. This can be reasoned that mutation may have affected these characteristics. However, the role of mutation involving these characteristics could not be studied. Therefore, it is necessary to do further study on these traits. In the previous reports, Kumbhar et al. [27] and Salem et al. [35] stated that it is difficult to discriminate close genotypes through phenotypic assessment. Furthermore, many agronomical characteristics such as quality and yield are highly affected by environmental conditions [36]. In another report, Lo et al. [37] indicated that in normal environmental conditions, rice mutants may not exhibit desirable phenotypes; subsequently, these mutants need to be recognized by screening under appropriate or inducible conditions.

Genetic variation in a population is a worthy source for enlarging the range of genetic materials in plant breeding, and molecular markers, such as SSRs and SNPs, are effective tools to discover genetic diversity [9]. Compared to other genetic markers, SSR markers have remarkable potential to discriminate between rice genotypes $[35,38]$. Classification of genotypes based on polymorphism markers is a prevailing mean for assessment of genetic variance $[27,38,39]$. PIC value is a principal factor in distinguishing the percentage of polymorphism of a marker at a specific locus; the higher PIC value is in SSR markers, the higher percentage of polymorphism is detected [38]. In this research, most SSR markers amplified more than two alleles among all genotypes. The PIC values of the 56 polymorphism markers indicates moderate genetic diversity among rice mutants, and seven markers showed great PIC values $(0.73<$ PIC $<0.79)$. Salem et al. [35] affirmed that markers with PIC values higher than 0.7 were very high PIC values, and they can be employed to enlarge the genetic foundation of the current genotypes. In addition, SSR markers with PIC value of 0.5 or higher considered as to be effective in discriminating the polymorphism rate $[10,38]$, and they have a potential in evaluation of genetic divergence. Therefore, when the level of polymorphism of markers was high (50\% highly informative markers followed with $43 \%$ moderately informative markers), it could indicate that the rice mutants used in this study were more diverse since only the amylose content trait-based DNA marker was used. The other explanation to this might be that the rice mutants have a related origin from quality rice. In previous study, Anumpam et al. [38] found that the genetic diversity value was low when using only SSR markers related to drought trait.

The UPGMA clustering analysis delineated all 19 genotypes in four groups with difference genotypes indicating the greatness of the genetic variation among the rice mutant genotypes. Cluster I represented six mutant genotypes originated from varieties and mutant lines, and the genetic similarity of this cluster was the lowest. It was significant that these genotypes were resolved into this cluster because they were originated from different rice cultivars. Some lines were generated from a common genotype, and they obviously grouped together, such as cluster II. $\mathrm{TK}_{1}, \mathrm{TK}_{2}$, and $\mathrm{TK}_{3}$ were originated from $\mathrm{T}$ and $\mathrm{K}$ varieties, and they grouped with $\mathrm{T}$ into this cluster. Interestingly, although $\mathrm{T}$ and $\mathrm{K}$ were parents of these lines, these lines clustered together with $\mathrm{T}$ (female parent) and separated from $\mathrm{K}$ (male parent); $\mathrm{K}$ was in cluster I, and the highest genetic similarity was found in this cluster. Although generated from a common genotype, some rice genotypes did not cluster together for instance $\mathrm{DDB}_{1}, \mathrm{DDB}_{2}, \mathrm{DDB}_{3}$, and $\mathrm{DDB}_{4}$; they clustered into different clusters while they have the same origin. Originated from $\mathrm{D}$ and $\mathrm{B}, \mathrm{DB}_{1}, \mathrm{DB}_{2}$, and $\mathrm{DB}_{3}$ were belong to cluster II; however, their parents belong to cluster I. This result was similar $\mathrm{STB}_{1}, \mathrm{STB}_{2}$, and $\mathrm{STB}_{3}$. These results could be reasoned that, mutation may change genetic materials, and these changes lead to the genetic differentiation among rice mutants. 
Aside from alleles obtained from polymorphism SSR markers, the differentiation within groups and among groups of nineteen rice genotypes was estimated. Based on the result of UPGMA clustering method, mutant genotypes and their parents were grouped into four groups with significant divergence among group $(p>0.001)$. By using AMOVA analysis, high genetic diversity within groups was reveal $(68 \%)$, whereas, among groups, genetic diversity was only $30 \%$. There was a significant genetic variation among rice mutants. Mao-bai et al. [40] previously referred that it may be due to farming system alteration. This can be explained that extensive cultivation may have contributed to the occurrence of rice mutants. Although the rice mutants used in this study were selected randomly, further investigation should be conducted on the other mutant lines to understand the influence of MNU mutation on the phenotypes and genotypes correlated to amylose content in rice. Findings of this study are helpful for controlling the amylose content in rice breeding, and for widening the understanding of MNU mutation to rice quality.

\section{Conclusions}

In this study, variation in the phenotype and genotype of rice mutants attained from the MNU mutation has provided clues for identification of the divergence of rice mutants. It has primarily provided valuable information on the rice mutant genotypes, as well as phenotypes. This may convey the potential to select desired traits to assist for breeding programs based on the relationship among traits and genetic diversity. The findings indicate that it is possible to obtain adequate polymorphism among rice mutants from above SSR makers, and it also elucidates the positions of SSR markers in exploring the genetic diversity among mutant genotypes. Furthermore, it may also assist in choosing an effective method to improve the target traits in rice breeding by MNU mutation.

Acknowledgments: The authors thank Ministry of Agriculture and Rural Development and Ministry of Education and Training of the Socialist Republic of Vietnam, to provide Truong Thi Tu Anh a scholarship. Do Tan Khang, Nguyen Thanh Quan, and Phung Thi Tuyen are appreciated for their assistance to this research.

Author Contributions: Truong Thi Tu Anh, conducted experiments and wrote manuscript under Tran Dang Xuan instruction. Tran Dang Khanh and Tran Dang Dat prepared rice materials. Tran Dang Xuan revised and approved the final revision. All authors corrected manuscript.

Conflicts of Interest: The authors declare no conflict of interest.

\section{References}

1. Bhat, F.M.; Riar, C.S. Effect of amylose, particle size \& morphology on the functionality of starches of traditional rice cultivars. Int. J. Biol. Macromol. 2016, 92, 637-644. [PubMed]

2. Jiang, Y.; Cai, Z.; Xie, W.; Long, T.; Yu, H.; Zhang, Q. Rice functional genomics research: Progress and implications for crop genetic improvement. Biotechnol. Adv. 2012, 30, 1059-1070. [CrossRef] [PubMed]

3. Zhao, X.; Zhou, L.; Ponce, K.; Ye, G. The usefulness of known genes/qtls for grain quality traits in an Indica population of diverse breeding lines tested using association analysis. Rice 2015, 8. [CrossRef] [PubMed]

4. Parry, M.A.J.; Madgwick, P.J.; Bayon, C.; Tearall, K.; Hernandez-Lopez, A.; Baudo, M.; Rakszege, M.; Hamada, W.; Al-Yassin, A.; Ouabbou, H.; et al. Mutation discovery for crop improvement. J. Exp. Bot. 2009, 60, 2817-2825. [CrossRef] [PubMed]

5. Sharma, A.; Singh, S.K. Induced mutation-A tool for creation of genetic variability in rice (Oryza sativa L.). J. Crop Weed. 2013, 9, 132-138.

6. Abacar, J.D.; Zhao-miao, L.; Xin-cheng, Z.; Cheng-qiang, D.; She, T.; Zheng-hui, L.; Shao-hua, W.; Yan-feng, D. Variation in yield and physicochemical quality traits among mutants of Japonica rice cultivar Wuyujing 3. Rice Sci. 2016, 23, 33-41. [CrossRef]

7. Oladosu, Y.; Rafii, M.Y.; Abdullah, N.; Hussin, G.; Ramli, A.; Rahim, H.A.; Miah, G.; Usman, M. Principle and application of plant mutagenesis in crop improvement: A review. Biotechnol. Biotechnol. Equip. 2016, 30, 1-16. [CrossRef]

8. Reig-Valiente, J.L.; Viruel, J.; Sales, E.; Marqués, L.; Terol, J.; Gut, M.; Derdak, S.; Talon, M.; Domingo, C. Genetic diversity and population structure of rice varieties cultivated in temperate regions. Rice 2016, 9. [CrossRef] [PubMed] 
9. Nachimuthu, V.V.; Muthurajan, R.; Duraialaguraja, S.; Sivakami, R.; Pandian, B.A.; Ponniah, G.; Gunasekaran, K.; Swaminathan, M.K.S.K.; Sabariappan, R. Analysis of population structure and genetic diversity in rice germplasm using SSR markers: An initiative towards association mapping of agronomic traits in Oryza sativa. Rice 2015, 8. [CrossRef] [PubMed]

10. Haritha, G.; Sudhakar, T.; Chandra, D.; Ram, T.; Divya, B.; Sarla, N. Informative ISSR markers help identify genetically distinct accessions of Oryza rufipogon in yield improvement. Rice Sci. 2016, 23, 225-241. [CrossRef]

11. Ram, S.G.; Thiruvengadam, V.; Vinod, K.K. Genetic diversity among cultivars, landraces and wild relatives of rice as revealed by microsatellite markers. J. Appl. Genet. 2007, 48, 337-345. [CrossRef] [PubMed]

12. Edzesi, W.M.; Dang, X.; Liang, L.; Liu, E.; Zaid, I.U.; Hong, D. Genetic diversity and elite allele mining for grain traits in rice (Oryza sativa L.) by association mapping. Front. Plant. Sci. 2016, 7, 1-13. [CrossRef] [PubMed]

13. Collard, B.C.Y.; Mackill, D.J. Marker-assisted selection: an approach for precision plant breeding in the twenty-first century. Philos. Trans. R. Soc. B 2008, 363, 557-572. [CrossRef] [PubMed]

14. Ni, J.; Colowit, P.M.; Mackill, D.J. Evaluation of genetic diversity in rice subspecies using microsatellite markers. Crop Sci. 2002, 42, 601-607. [CrossRef]

15. Akagi, H.; Yokozeki, Y.; Inagaki, A.; Fujimura, T. Highly polymorphic microsatellites of rice consist of AT repeats, and a classification of closely related cultivars with these microsatellite loci. Theor. Appl. Genet. 1997, 94, 61-67. [CrossRef] [PubMed]

16. Sega, G.A. A review of the genetic effects of ethyl methanesulfonate. Mutat. Res. 1984, 134, $113-142$. [CrossRef]

17. Vogel, E.W.; Natarajan, A.T. DNA damage and repair in somatic and germ cells in vivo. Mutat. Res. 1995, 330, 183-208. [CrossRef]

18. Greene, E.A.; Codomo, C.A.; Taylor, N.E.; Henikoff, J.G.; Till, B.J.; Reynolds, S.H.; Enns, L.C.; Burtner, C.; Johnson, J.E.; Odden, A.R.; et al. Spectrum of chemically induced mutations from a large-scale reversegenetic screen in Arabidopsis. Genetics 2003, 164, 731-740. [PubMed]

19. Till, B.J.; Cooper, J.; Tai, T.H.; Colowit, P.; Greene, E.A.; Henikoff, S.; Comai, L. Discovery of chemical induced mutations in rice by TILLING. BMC Plant Biol. 2007, 7, 19. [CrossRef] [PubMed]

20. Satoh, H.; Shibahara, K.; Tokunaga, T.; Nishi, A.; Tasaki, M.; Hwang, S.K.; Okita, T.W.; Kaneko, N.; Fujita, N.; Yoshida, M.; et al. Mutation of the plastidial $\alpha$-glucan phosphorylase gene in rice affects the synthesis and structure of starch in the endosperm. Plant Cell 2008, 20, 1833-1849. [CrossRef] [PubMed]

21. Shah, S.M.; Arif, M.; Aslam, K.; Shabir, G.; Thomson, M.J. Genetic diversity analysis of Pakistan rice (Oryza sativa) germplasm using multiplexed single nucleotide polymorphism markers. Genet. Resour. Crop Evol. 2016, 63, 1113-1126. [CrossRef]

22. Xuan, T.D.; Khanh, T.D.; Anh, T.T.T. Possibility of breeding super rice cultivars using gene linkage. In Proceedings of the 9th Asian Crop Science Association Conference (9th ACSAC), Jeju, Korea, 5-7 June 2017.

23. Yi, M.; New, K.T.; Vanavichit, A.; Chai-arree, W.; Toojinda, T. Marker assisted backcross breeding to improve cooking quality traits in Myanmar rice cultivar Manawthukha. Field Crops Res. 2009, 113, 178-186. [CrossRef]

24. Jin, L.; Lu, Y.; Xiao, P.; Sun, M.; Corke, H.; Bao, J. Genetic diversity and population structure of a diverse set of rice germplasm for association mapping. Theor. Appl. Genet. 2010, 121, 475-487. [CrossRef] [PubMed]

25. Murray, M.G.; Thompson, W.F. Rapid isolation of high molecular weight plant DNA. Nucleic Acids Res. 1980, 8, 4321-4325. [CrossRef] [PubMed]

26. Tello-Ruiz, M.K.; Stein, J.; Wei, S.; Preece, J.; Olson, A.; Naithani, S.; Amarasinghe, V.; Dharmawardhana, P.; Mulvaney, J.; Kumari, S.; et al. Gramene 2016: Comparative plant genomics and pathway resources. Nucleic Acids Res. 2016, 44, D1133-D1140. [CrossRef] [PubMed]

27. Kumbhar, S.D.; Kulwal, P.L.; Patil, J.V.; Sarawate, C.D.; Gaikwad, A.P.; Jadhav, A.S. Genetic diversity and population structure in landraces and improved rice varieties from India. Rice Sci. 2015, 22, 99-107. [CrossRef]

28. Nagy, S.; Poczai, P.; Cernák, I.; Gorji, A.M.; Hegedus, G.; Taller, J. PICcalc: An online program to calculate polymorphic information content for molecular genetic studies. Biochem. Genet. 2012, 50, 670-672. [CrossRef] [PubMed]

29. Peakall, R.; Smouse, P.E. GENALEX 6: Genetic analysis in Excel. Population genetic software for teaching and research. Mol. Ecol. Notes 2006, 6, 288-295. [CrossRef] 
30. Koutroubas, S.D.; Mazzini, F.; Pons, B.; Ntanos, D.A. Grain quality variation and relationships with morpho-physiological traits in rice (Oryza sativa L.) genetic resources in Europe. Field Crops Res. 2004, 86, 115-130. [CrossRef]

31. Huang, R.; Jiang, L.; Zheng, J.; Wang, T.; Wang, H.; Huang, Y.; Hong, Z. Genetic bases of rice grain shape: So many genes, so little known. Trends Plant Sci. 2013, 18, 218-226. [CrossRef] [PubMed]

32. Tan, Y.F.; Xing, Y.Z.; Li, J.X.; Yu, S.B.; Xu, C.G.; Zhang, Q. Genetic bases of appearance quality of rice grains in Shanyou 63, an elite rice hybrid. Theor. Appl. Genet. 2000, 101, 823-829. [CrossRef]

33. Xu, Z.; Chen, W.; Ma, D.; Lu, Y.; Zhou, S.; Liu, L. Correlations between rice grain shapes and main qualitative characteristics. Acta Agron. Sin. 2004, 30, 894-900.

34. Lou, J.; Chen, L.; Yue, G.; Lou, Q.; Mei, H.; Xiong, L.; Luo, L. QTL mapping of grain quality traits in rice. J. Cereal Sci. 2009, 50, 145-151. [CrossRef]

35. Salem, K.F.M.; Sallam, A. Analysis of population structure and genetic diversity of Egyptian and exotic rice (Oryza sativa L.) genotypes. C. R. Biol. 2016, 339, 1-9. [CrossRef] [PubMed]

36. Hashemi, F.S.G.; Rafii, M.Y.; Ismail, M.R.; Mohamed, M.T.M.; Rahim, H.A.; Latif, M.A.; Aslani, F. The genetic and molecular origin of natural variation for the fragrance trait in an elite Malaysian aromatic rice through quantitative trait loci mapping using SSR and gene-based markers. Gene 2015, 555, 101-107. [CrossRef] [PubMed]

37. Lo, S.F.; Fan, M.J.; Hsing, Y.I.; Chen, L.J.; Chen, S.; Wen, I.C.; Liu, Y.L.; Chen, K.T.; Jiang, M.J.; Lin, M.K.; et al. Genetic resources offer efficient tools for rice functional genomics research. Plant Cell Environ. 2016, 39, 998-1013. [CrossRef] [PubMed]

38. Anupam, A.; Imam, J.; Quatadah, S.M.; Siddaiah, A.; Das, S.P.; Variar, M.; Mandal, N.P. Genetic diversity analysis of rice germplasm in Tripura State of Northeast India using drought and blast linked markers. Rice Sci. 2017, 24, 10-20. [CrossRef]

39. Hashimoto, Z.; Mori, N.; Kawamura, M.; Ishii, T.; Yoshida, S.; Ikegami, M.; Takumi, S.; Nakamura, C. Genetic diversity and phylogeny of Japanese sake-brewing rice as revealed by AFLP and nuclear and chloroplast SSR markers. Theor. Appl. Genet. 2004, 109, 1586-1596. [CrossRef] [PubMed]

40. Mao-bai, L.; Hui, W.; Li-ming, C. Evaluation of population structure, genetic diversity and origin of Northeast Asia weedy rice based on simple sequence repeat markers. Rice Sci. 2015, 22, 180-188. [CrossRef] 